\title{
À prova do estrangeiro, Oliveira em francês
}

Mathias Lavin

Universidade de Paris III

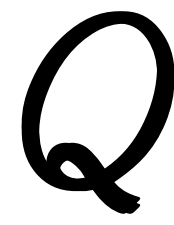

uando da publicação do Princípio da incerteza (2002), Manoel de Oliveira, citando o Padre Antônio Vieira, declarou: "O padre Antônio Vieira afirmava que nós, portugueses, temos uma terra para nascer e todo um mundo para morrer". ${ }^{1}$ À primeira vista, a fórmula pode surpreender, pois o cineasta do Porto parece inserido em uma cultura e mesmo em uma região bem circunscritas, e que seu filme-resumo, Non, ou a vã glória de mandar (1989), tinha desconstruído com ironia o imaginário das Descobertas. Seguramente, a ambição artística aspira a um brilho universal, mas Oliveira faz, sem dúvida alguma, alusão a outra coisa: a necessária consideração da existência de uma diferença para assumir sua identidade. De maneira mais precisa, é inegável que suas obras, em particular as mais recentes, tenham se alimentado de elementos estrangeiros e que tenham efetuado verdadeiras passagens por outras culturas. Penso aqui especificamente, e me fixarei neste aspecto durante o decorrer do texto, pelo fato de que, há mais de vinte anos, um número representativo de seus filmes tem sido realizado em francês, às vezes na França, enquanto que, no início dos anos 1980, toda a sua produção tinha sido feita entre Lisboa e o Porto, sob a

${ }^{1}$ In: "Os meus filmes são gritos", entrevista com Manoel de Oliveira por Fernando Da Costa, Visão, 14 de novembro de 2002. 
dupla referência tutelar de José Régio e Camilo Castelo Branco. Importa então precisar o estatuto dessas migrações de uma língua a outra, e de um país a outro, devidas, certamente em parte, a razões práticas de co-produção européia, mas que não são sem consequências formais significativas em um cinema que privilegia a palavra. Trata-se de uma obra submetida concretamente à prova do estrangeiro que é preciso aqui evocar.

Lembremo-nos de início que, se a obra do cineasta sempre se beneficiou de um reconhecimento inegável em seu país, ela sempre ficou ambivalente e que, ao mesmo tempo, os elogios vindos de observadores estrangeiros contribuíram fortemente para o prestígio que ela tem hoje em dia. A recepção de Amor de perdição (1978) foi o exemplo mais convincente, principalmente porque teve consequências sobre o prosseguimento extraterritorial da obra de Oliveira. Esta adaptação do célebre romance de Camilo Castelo Branco foi difundida em vários episódios na televisão nacional, e desencadeou uma campanha de difamação do cineasta por uma grande parte dos meios de comunicação, acusando-o de ter dilapidado os subsídios recebidos para a realização do filme, e de ter traído o espírito da obra. Projetado na França e na Itália durante retrospectivas consagradas ao cinema português, o filme suscitou, ao contrário, um vivo entusiasmo, o que permitiu sua difusão em Paris e, devido a seu sucesso inesperado, a organização de novas projeções em Portugal, um ano após sua acolhida desastrosa. Na continuidade do interesse crescente por Oliveira, que se deu logo em seguida na França, o cineasta pôde trabalhar em relação direta com este país e começar a realizar filmes em francês.

No que diz respeito à presença do francês nos filmes de Oliveira, podemos distinguir três casos principais. Primeiro, quando a relação com a língua (a francesa) é fortemente mediatizada pela obra literária adaptada, ou servindo de fonte de inspiração. Le soulier de satin (1985) é o primeiro filme (dos mais longos, por sua ambição e duração) dirigido por Oliveira 
em uma língua estrangeira. Convidado por Jack Lang, então novo ministro da cultura, a realizar uma obra de sua escolha, Oliveira aceitou a proposta e optou pela peça de Claudel. Após uma longa preparação, a filmagem se deu em Lisboa, nos velhos estúdios da Tobis Portuguesa, mas em francês, apesar de muitos atores portugueses terem papéis importantes, a começar pelo personagem Rodrigues, vivido por Luís Miguel Cintra, em sua primeira aparição na obra oliveiriana. Este filme, fortemente teatralizado, utiliza o espaço como equivalente permanente de uma cena. Assim, o lugar da filmagem poderia ter sido qualquer localidade, ficando a importância dada aos cenários a fim de se insistir sobre o artifício da representação e sobre o valor do texto falado pelos personagens.

O fenômeno é comparável no filme seguinte, O meu caso (1986). A filmagem teve lugar no teatro de Le Havre e não em Portugal, mas lá, ainda, é o trabalho sobre a cena como metáfora do mundo que prevalece. $\mathrm{O}$ efeito de deslocamento entre as culturas é sem dúvida mais forte do que em Le soulier, pois o filme é uma adaptação da peça de José Régio O meu caso, de onde lhe vem o título. Além da curta peça de Régio, Oliveira utilizou um texto de Beckett (um irlandês escrevendo em francês) e trechos do Livro de Jó. De novo, o principal papel é de Cintra. Não é de forma alguma anódino que, para suas primeiras experimentações francesas, Oliveira tenha escolhido um ator português como intérprete principal. $O$ francês deste ator excepcional é impecável (assim como o de Oliveira) mas subsiste em sua dicção um leve sotaque indicando com clareza sua origem. Desta forma, a palavra gravada mantém-se como portadora de um desvio manifesto, fazendo com que o sotaque implique esta "incapacidade de uma semelhança absoluta, de um mimetismo perfeito", como escreveu Alain Fleischer. ${ }^{2}$ Em

${ }^{2}$ FLEISCHER, 2005, p. 78. 
razão desta defasagem em relação ao uso supostamente neutro e médio da língua, a palavra assume então uma ressonância singular, um pouco estranha, convidando à redescoberta de seus poderes.

Neste conjunto francófono, é preciso inserir, enfim, um filme diferente dos precedentes pelo seu tratamento do espaço, A carta (1999), inteiramente rodado em Paris, em vários lugares reconhecíveis (Père-Lachaise, Port-Royal, Jardin du Luxembourg, etc.) e em certos lugares ligados à cultura lusófona (a fundação Calouste Gulbenkian, onde os personagens assistem a um concerto de Maria João Pires, depois a um recital de Pedro Abrunhosa). Inspirado em A princesa de Clèves, o filme ancorase na realidade contemporânea, deixando por isso uma curiosa impressão de anacronismo. Entretanto, não é unicamente esta diferença temporal que confere a $A$ carta sua qualidade, mas igualmente a distância entre duas línguas, o francês e o português. A maior parte dos atores é francesa, em primeiro lugar Chiara Mastroianni (vivendo a moderna Princesa de Clèves), mas não se pode esquecer da importância de Pedro Abrunhosa (o equivalente de M. de Nemours) e, em um papel secundário, mas decisivo, Leonor Silveira, familiar ao cinema de Oliveira, que vive uma religiosa. É esta última quem fecha o filme com a leitura da famosa carta. Esta leitura supre a ausência da heroína, colocada definitivamente de lado - ela decidiu participar de uma missão humanitária na África. A antiga confidente de Madame de Clèves não está mais, a partir de agora, em posição de escuta; ela lê o texto escrito por sua amiga, em um gesto de apropriação da palavra do outro. $\mathrm{O}$ sotaque de Leonor Silveira é tão discreto quanto o de Luís Miguel Cintra, mas não é menos insistente, como uma dimensão espectral vindo habitar a língua francesa, como se fosse preciso uma ligeira inflexão para que se consiga ouvir as sonoridades e o ritmo de nossa língua cotidiana. Esta diferença é, também, 
o gesto soberano do artista que pode assim marcar sua obra com este detalhe linguístico.

A segunda possibilidade praticada pelo realizador se insere em um conjunto de filmes multilingues, cujo exemplo mais rico é Palavra e utopia (2000), onde ouve-se falar português, às vezes com sotaque brasileiro, latim, italiano e um pouco de dialeto tupi. A língua utilizada, de forma majoritária, continua sendo, entretanto, o português. Não é o caso de outros filmes que misturam várias línguas, privilegiando a relação francês / português como em O convento (1995); francês, português e inglês como em Party (1996); e francês, português como em Viagem ao princípio do mundo (1997). Essa última obra coloca de maneira direta a questão da língua materna. $O$ filme apresenta uma trupe de cinema que, descansando das filmagens, parte à procura da tia de um ator francês no norte de Portugal. Na primeira parte, um "importante e velho diretor", vivido por Marcello Mastroianni, faz desfilarem suas lembranças de juventude que, de fato, são as de Manoel de Oliveira; na segunda parte, trata-se principalmente da evocação do pai do ator, saído de sua aldeia natal no Minho para tentar a sorte na França. Duas vidas são assim postas em paralelo, e o problema da diferença das línguas assume toda sua importância, notadamente quando a velha tia recusa reconhecer seu sobrinho na pessoa do ator porque ele não sabe uma palavra de português. $\mathrm{O}$ esquecimento da língua de origem aparece aos olhos do personagem como o índice de uma impossível filiação. Mas o mais significativo é que Oliveira tenha escolhido um intérprete italiano para ser seu substituto e que este só se exprima em francês durante todo o filme. A viagem à origem do mundo suscita, assim, a imagem de uma dispersão das línguas.

É esta que organiza verdadeiramente Um filme falado (2003), que multiplica os idiomas (português, francês, italiano, grego e inglês), notadamente na longa sequência do jantar no barco onde se reúnem o capitão (John Malkovich), marinheiro 
polonês que optou pelo uso do inglês contra a vontade de Conrad, e suas três convidadas (Catherine Deneuve, Stefania Sandrelli e Irene Papas). Cada um se exprime em sua língua de origem e todos se entendem sem a necessidade de um tradutor, em uma perfeita "intercomunicação poliglota", como precisa o comandante. Sem dúvida, esta assembleia representa seres fora do comum, divindades (do cinema) que, pelo menos de maneira metafórica, não falam a linguagem dos simples mortais - aliás, a professora de história, vivida por Leonor Silveira, juntamente com sua filha ficam de lado durante o jantar. Como conseguir se compreender após Babel? Parece se perguntar o cineasta. Sem dúvida, a diversidade de línguas é para Oliveira a diferença a partir da qual se constrói a civilização, problema principal que o filme coloca em jogo. Não há volta a uma língua única (em uma concepção que será então dirigida contra Babel), mas sim a idéia de que a diversidade de línguas é uma sorte que traz em si mesma, e ao mesmo tempo, um risco. Este resulta de uma possível incompreensão simbolizada pelo sacrifício da professora de história e sua filha, vítimas de um atentado terrorista. Não é somente o futuro que é, então, condenado, mas também a possibilidade mesma da memória e da capacidade de fabulação, já que não é mais possível fazer conviverem diferentes idiomas.

A terceira possibilidade a se levar em conta diz respeito aos filmes rodados na França e em francês, nos quais Oliveira trabalhou em uma perspectiva que chamarei de retrato em espelho. Dois filmes (até agora) entram nessa categoria: Vou para casa (2001) e Belle toujours (2007). Essas obras têm a ver com o gênero do auto-retrato, praticado por Oliveira em Porto da minha infância (2001), ao propor uma imagem do criador pela mediação de seu intérprete principal. Não se trata mais de tornar perceptível um sotaque, de questionar de maneira direta a existência da língua materna ou de brincar com a pluralidade das línguas. Graças à atenção dada a um ator privilegiado, 
Michel Piccoli, nos dois exemplos considerados, a língua do outro se torna um meio para se aproximar de si, escapando ao mesmo tempo do fechamento narcísico ou do mito de uma pureza da língua materna ou nacional. ${ }^{3}$ Trata-se de um ator francês que é utilizado por Oliveira para passar este gesto, bastante raro, onde ator e cineasta parecem solidários sem se confundirem e sem que aquele sirva de porta-voz ou de simples substituto deste. Assim, em Vou para casa e Belle toujours, Michel Piccoli constitui uma figura na qual intérprete e criador se refletem mutuamente. Igualmente, na passagem de uma língua a outra, parece haver harmonia, mas esta não é sem perigo. Isto é tematizado de maneira evidente em Vou para casa, onde o uso da língua inglesa se revela dramática para Gilbert Valence, o ator exigente, vivido por Piccoli. Com efeito, este se revela incapaz de memorizar o texto de Buck Mulligan em uma improvável adaptação televisiva do Ulisses, de Joyce (referência que permite reintroduzir a idéia de um caos das línguas). Após seus fracassos intransponíveis durante os ensaios, Valence deixa o lugar de filmagem, vagueia em seguida por ruas balbuciando suas falas, e reencontra em seguida sua casa, cujos degraus da escada sobe lentamente como se entrasse em sua última morada. O título do filme não é anódino, e voltar a casa equivale a voltar a si mesmo para aí morrer depois de ter

${ }^{3} \mathrm{O}$ que, a propósito da tradução, escreve Antoine Berman, a quem, como homenagem, pedimos emprestado o título deste artigo, diz respeito ao que está em jogo no empreendimento de Oliveira: " $\mathrm{O}$ objetivo da tradução - permitir no nível do escrito uma certa relação com o Outro, fecundar o Próprio pela mediação do Estrangeiro - choca-se de frente com a estrutura etnocêntrica de toda cultura ou esta espécie de narcisismo que faz com que toda sociedade gostaria de ser um Todo puro e não misturado". (BERMAN, 1984, p. 16). 
fracassado no domínio de uma língua estrangeira. Entretanto, este horizonte mórbido não resume todo o pensamento do cineasta, mais próximo da ironia diabólica do que do lamento melancólico. Belle toujours, o outro filme onde Piccoli encarna um verdadeiro alter ego do cineasta, se baseia em um jogo de palavras, em francês, relativo ao título do filme de Buñuel, Belle de jour, sobre o qual ele opera uma sutil variação, e o "toujours" parece conjurar o fim de um ciclo ou de uma carreira. Piccoli é aqui mais indolente e extravagante que no filme precedente, sendo seu personagem mais taciturno e à vontade quando, por exemplo, guarda para si, no fim do filme, o dinheiro encontrado na bolsa de Séverine (vivida por Bull Ogier), bolsa esta esquecida quando ela, precipitadamente, deixa o jantar que reuniu os dois protagonistas. Esta diferença de caracterização do personagem fornece, assim, uma imagem da relação de Oliveira com a outra língua utilizada em seus filmes, aquela que lhe permite ao mesmo tempo mais simplicidade e mais desenvoltura. E que alimenta permanentemente uma obra que fez da volta seu caminho privilegiado. Como disse Claudel, em português, para servir de legenda ao Soulier de satin: "Deus escreve direito por linhas tortas".

Tradução: Sergio Alves Peixoto Universidade Federal de Minas Gerais

\section{Bibliografia}

BERMAN, A. L'Epreuve de l'étranger, culture et traduction dans l'Allemagne romantique. Paris: Gallimard, 1984.

FLEISCHER, Alain. L'accent, une langue fantôme. Paris: Seuil, 2005. 